\title{
Identificación de Scleroderma citrinum Pers en una plantación de almendros de la ciudad de Villa Alemana, Chile.
}

\author{
(Identification of Scleroderma citrinum Pers in an almond tree plantation \\ from Villa Alemana city, Chile.)
}

Rodrigo Cruz Ch.*, Laura Carvajal S., Salomon Perez G.

Laboratorio de Micología. Universidad de Valparaíso.

*Autor para correspondencia: rodrigo.cruz@uv.cl

RECIBIDO:06 de Noviembre de 2017

APROBADO:04 de Diciembre de 2017

DOI: 10.22370/bolmicol.2017.32.1.1062

LOS AUTORES DECLARAN NO TENER CONFLICTO DE INTERESES

Palabras clave: Scleroderma citrinum, identificación, almendros.

Keywords: Scleroderma citrinum, Identification, almond tree.

\section{RESUMEN}

Las micorrizas son una asociación mutualista fundamental para el desarrollo tanto de las plantas como para los hongos que la establecen. Son comunes en bosques y existen muchas especies de hongos que realizan esta asociación. Las ectomicorrizas son hifas de un hongo que penetran las raíces secundarias de la planta para desarrollarse, rodeando las células de la corteza de las raices. En este trabajo se reporta el hallazgo de la ectomicorriza Scleroderma citrinum en un predio con almendros en la ciudad de Villa Alemana, Quinta región de Chile, lugar donde no había sido descrita. Tanto las condiciones ambientales, como las características del suelo del lugar no son las más favorables para el desarrollo de esta especie.

\section{ABSTRACT}

Micorrhizae are mutualistic association between plants and fungus, which is fundamen- tal for the both of them. They are common in forest and many species of fungus are involved in this association. Ectomicorrhizae are a group of hyphae that penetrate the secondary roots of a plant, surrounding the cortex cells to develop. In the present report we inform the ectomicorrhizae Scleroderma citrinum finding in a location with almond tree plantation at Villa Alemana city V region of Chile, place where it never been found out before. Both the environmental condition and the soil characteristics are not the best for the development of this specie.

\section{INTRODUCCIÓN}

Las ectomicorrizas cumplen un rol fundamental en el crecimiento, resistencia a patógenos de las plantas, y en el ciclo de nutrientes en los ecosistemas forestales (1). Se trata de una asociación mutualista prácticamente universal, ya que muchas de las especies vegetales la establecen de forma natural en ambientes muy diversos $(1,2)$. Se estima que aproximadamente el $95 \%$ de las 
plantas en sus hábitats naturales forman una relación mutualista con micorrizas y que las hifas de los hongos pueden llegar a explorar entre 100 a 1.000 veces más terreno que las propias raíces de las plantas (3). Esta relación provee al hongo de manera constante y directa, entre el 10 al 30\% del total de carbohidratos (monómericos y diméricos) producidos en la fotosíntesis, y de vitaminas metabolizadas en otros procesos internos de la planta. Por su parte la planta puede utilizar la amplia red de micelios del hongo para absorber agua y/o nutrientes desde el suelo. Las micorrizas son especialmente beneficiosas para plantas en terrenos pobres en nutrientes, y se ha demostrado que entregan resistencia a ciertos patógenos, mayor tolerancia a la sequía y alivia también el estrés de la planta mediante el secuestro de metales pesados en el suelo $(2,3,4)$.

Con el cultivo de especies arbóreas exóticas como Pinus radiata, se han introducido al país varias especies de hongos cuyos carpóforos pueden ser comestibles, y en los últimos años han llegado a ser un producto de exportación (5). $S$. citrinum es una especie abundante en plantaciones de $P$. radiata, formando asociación ectomicorrícica con estos árboles. Se señala que es muy abundante en suelos arenosos y escasa en suelos rojos, teniendo los carpóforos menor tamaño en este último. Es de distribución gregaria o cespitosa, epigeo en el suelo o humus con musgos, a veces en la madera podrida (6). En el mundo se ha asociado a los géneros Castanea, Quercus, Fagus, Nothofagus y Pinus (7). Su uso culinario es discutido, siendo consumido en algunos países de Europa del este. En Chile se distribuye principalmente entre Concepción y Magallanes, fructifica desde finales de Abril a Junio y a veces en Septiembre (5).

El objetivo del presente trabajo es reportar la identificación de $S$. citrinum asociado a una plantación de almendros en la Quinta Región de Valparaíso.

\section{MATERIALES Y MÉTODOS}

Los carpóforos fueron recolectados de un predio de $5000 \mathrm{~m}^{2}$ plantados con almendros, en la ciudad de Villa Alemana, Región de Valparaíso, Chile.

Se analizaron las características macro y micromorfológicas de la especie en el Laboratorio de Micología de la Universidad de Valparaíso con el uso de una lupa estereoscópica marca Zeiss modelo Stemi 2000-C y un microscopio óptico marca Leica modelo DM500.

\section{Identificación de la especie}

Los carpóforos encontrados estaban principalmente aislados y algunos cespitosos de 2-4 ejemplares unidos, globosos de 4-6 cm de diámetro, escamosos, con pequeñas grietas apicales y surcos longitudinales. Peridio con grosor de 3 mm aproximadamente, duro, coriáceo. Gleba pulverulenta color marrón-negruzco. Hifas tabicadas y fibuladas. sporas globosas, color café de 11-12 $\mu \mathrm{m}$ de diámetro, ornamentación de 2-3 $\mu \mathrm{m}$, reticuladas. Basidios cilíndricos-claviformes (imágenes $1,2,3)$.

\section{DISCUSION}

El término micorriza significa "hongoraíz", fue propuesto por Frank en 1885 para definir asociaciones simbióticas ("vivir conjuntamente dos o más organismos") mutualistas, es decir no patógenas, entre raíces de plantas y micelios de hongos, en las que ambos resultan beneficiados (8). Esta coevolución se remonta al Paleozoico, hace más de 400 millones de años, con el origen de las primeras plantas terrestres (8). En todos los tipos de micorrizas se establece una interfase de contacto íntima entre las hifas y las células vegetales, donde se produce el intercambio de nutrientes de manera bidireccional (los nutrientes minerales 
disueltos en agua desde el hongo a la planta, mientras ésta cede al hongo los azúcares que se originan en la fotosíntesis). En el caso de orquídeas y plantas aclorofílicas este flujo suele ser unidireccional, desde el hongo a las raíces de las plantas (9). En las ectomicorrizas las hifas de un hongo penetran las raíces secundarias de la planta para desarrollarse, rodeando las células de la corteza radical, y forman una trama intercelular denominada red de Hartig, además de una capa de micelio en la parte exterior de la raíz, llamada manto $(9,10)$

S. citrinum fue descrito por primera vez en 1801 por Christian Hendrik Persoon (11). Es una ectomicorriza muy común y ampliamente distribuida en toda la Europa occidental y el este de América del Norte, no obstante se ha reportado en todos los continentes, asociada tanto a especies nativas, como introducidas. En América destacan los reportes de México, Argentina y Brasil $(12,13,14)$. En Chile, se ha descrito su presencia principalmente desde la región del Bio-Bio al sur $(5,15)$. En este reporte se describe la presencia de esta especie en la región de Valparaíso, la cual presenta un clima que no favorecería el desarrollo de esta especie, templado con variaciones de temperaturas menores por el influjo del océano, siendo más parejas durante el año, con un promedio anual de $14^{\circ}$. La humedad relativa es alta con un $75 \%$ y las precipitaciones alcanzan unos $450 \mathrm{~mm}$ (16), muy distinto al clima del sur de Chile donde aumenta la humedad y las

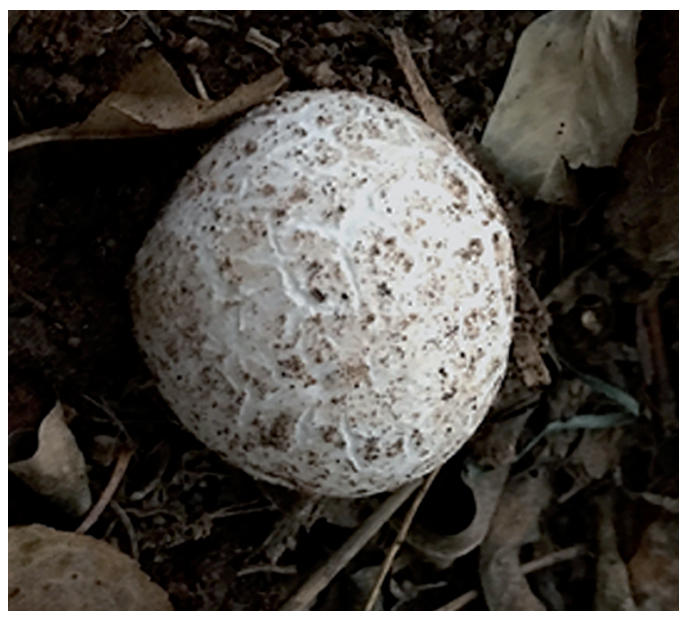

lluvias pueden superar los $2000 \mathrm{~mm}$ al año (16).

S. citrinum se asocia con frecuencia a ciertos árboles nativos, y en países como el nuestro a especies exóticas introducidas como es el caso de $P$. radiata. Esta especie no había sido reportada en asociación a árboles frutales, sin embargo, es conocida su capacidad de formar asociaciones mutualísticas con múltiples especies de árboles $(15,17)$. Los ejemplares estudiados se encontraron en suelo arcilloso de la ciudad de Villa Alemana, asociados a una plantación de almendros. Este tipo de suelo no favorecería el desarrollo de esta especie, la cual ha sido descrita principalmente en suelos boscosos $\mathrm{y}$ arenosos (5).

En la actualidad ha habido un importante desarrollo y entendimiento de las micorrizas, y la ecotecnología las ha utilizado para la producción de viveros forestales debido a su potencial para aumentar el crecimiento y vigor de las plántulas. De esta forma, el uso de estos hongos puede ayudar a reducir el aporte de fertilizantes y pesticidas, evitando la contaminación del suelo y los recursos hídricos (17).

\section{AGRADECIMIENTOS}

A Eduardo Valenzuela (QEPD) de la Universidad Austral de Valdivia por la ayuda en la identificación de la especie.

Figura 1. Carpóforo globosos de $6 \mathrm{~cm}$ de diámetro, escamoso, con grietas superficiales. 


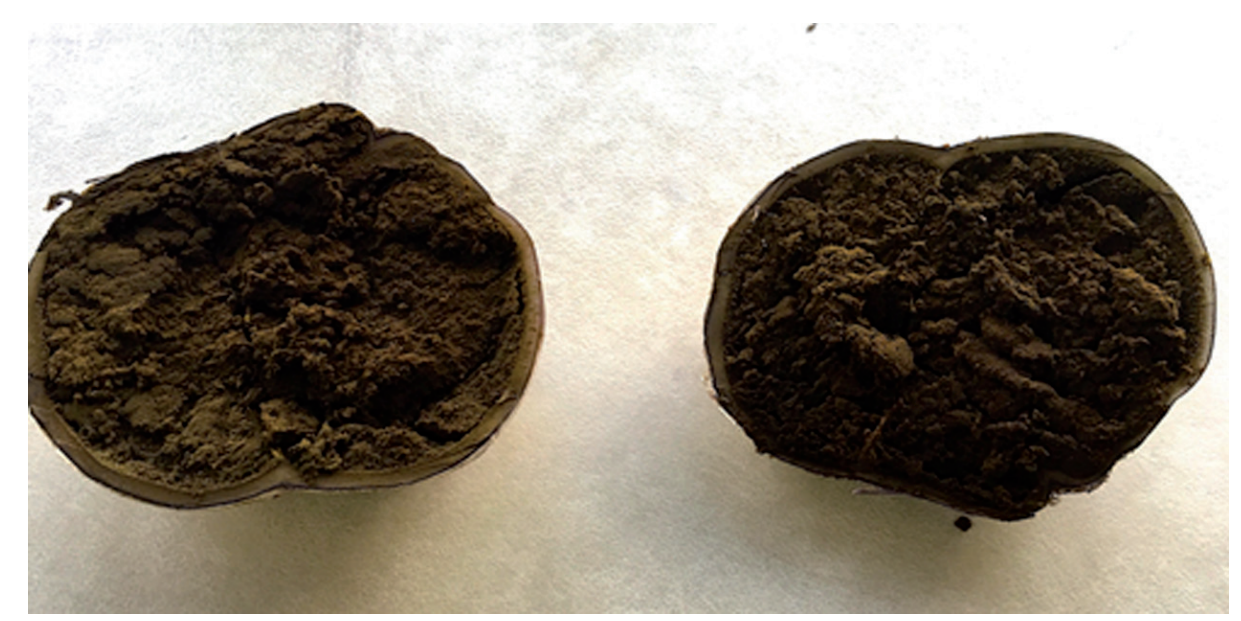

Figura 2. Gleba pulverulenta color marrón-negruzco.

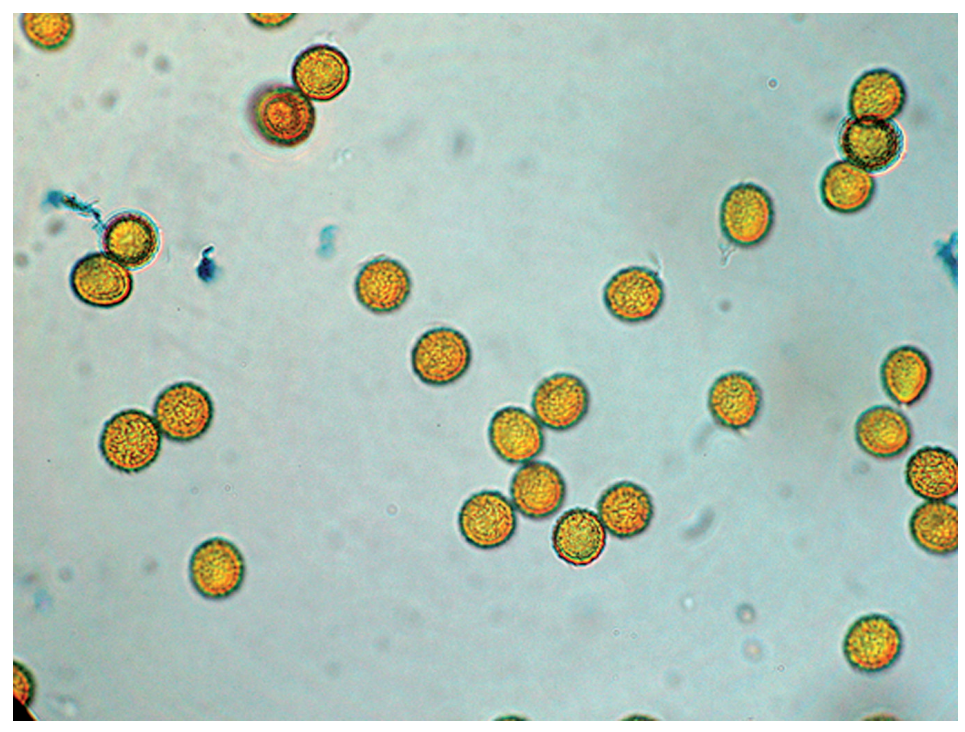

Figura 3. Esporas globosas de 11-12 $\mu \mathrm{m}$ de diámetro.

\section{REFERENCIAS}

1. Salusso M, Moraña L. Ectomycorrhizal community structure in pinaceous forest from Altos La Sierra, Argentina. Rev Chil de Historia Natural.1995; 68:509-513.

\section{Calvet M, Camprubí A, Balada A, Morera}

C. Utilization of arbuscular mycorrhizae for the production of citrus rootstock cultivars in spanish nurseries. Centre de coopération internationale en recherche agronomique pour le developpment
(GIRAD). $5^{\circ}$ Congreso Mundial de viveristas de cítricos. Montpellier, 5 - 8 de marzo de 1997. s.p.

3. González M, Quiroz I, Travieso R, Chung P, García E. Determinación de medios de cultivo y ph para la masificación in vitro de cepas de Suillus luteus Aubl. Asociadas a Pinus radiata d. Don Y Scleroderma citrinum Pers. Asociadas a Eucalyptus globulus Labill. De la región del biobío, chile. Rev. Árvore. 2015; 39(1):105-113 
4. Smith S, Smith F, Jakobsen I. Functional diversity in arbuscular mycorrhizal (am) symbioses: the contribution of the mycorrhizal $\mathrm{p}$ uptake pathway is not correlated with mycorrhizal responses in growth or total P uptake. New Phytologist. $2004 ; 162: 511-534$

5. Valenzuela E. Hongos comestibles silvestres colectados en la $\mathrm{x}$ region de chile Bol. Micol. 2003; 18: 1-14

\section{Guzmán G, Cortés-Pérez A, Guzmán-Dáva-} los L, Ramírez-Guillén F, del RefugioSánchezJácome M. Una emendación de Scleroderma, nuevos registros y revisión de las especies conocidas en México. Rev. Mex. Biodiv.2013; 84: S173-S191

7. Mrak T, Kühdorf K, Grebenc T, Štraus I, Münzenberger B, Kraigher H. Scleroderma areolatum ectomycorrhiza on Fagus sylvatica L. Mycorrhiza. 2017; 27(3):283-293

8. Honrubia M. Las micorrizas: una relación planta-hongo que dura más de 400 millones de años. Anales del Jardín Botánico de Madrid. 2009: 66S1: 133-144.

9. Honrubia M, Morte A, Díaz G. Dinamismo del componente fúngico micorrícico y su incidencia en la regeneración del bosque mediterráneo. In: Charco, J. (coord.), La regeneración natural del bosque mediterráneo en la península Ibérica: evaluación de problemas y propuesta de soluciones. ARBAMMA (eds.);2009.

10. Peterson R L, Farquhar M L. Mycorrhizas
Integrated development between roots and fungi. Mycologia. 1994; 86 (3): 311-326.

11. Persoon C H. Synopsis methodica fungorum. Gottingae: Apud H. Dieterich, 1801.

12. Carrillo-González $R$, González-Chávez $M$. Tolerance to and accumulation of cadmium by the mycelium of the fungi Scleroderma citrinum and pisolithus tinctorius. Biological Trace Element Research. 2012; 146(3):388-395

13. Nouhra E, Hernández $M$, Pastor $\mathbf{N}$, Crespo E. The species of Scleroderma from Argentina, including a new species from the Nothofagus forest. Mycologia. 2012; 104(2): 488-495.

14. Gurgel FE, Silva BDB, Baseia IG. New records of Scleroderma from Northeastern Brazil. MYCOTAXON.2008; 105: 399-405

15. Garrido N. Contribución al conocimiento de los Agaricales (Mycota-Basidiomycetes) en plantaciones de Pinus radiata D. Don en la Octava Región de Chile. [Tesis]. Concepción: Dept. Botánica, Universidad de Concepción; 1981

16. Biblioteca del Congreso Nacional de Chile [sede Web]. Valparaiso: bcn.cl; [20 de diciembre de 2017]. Disponible en https://www.bcn.cl/siit/ nuestropais/region5/clima.htm

17. Calvaruso C, Turpault M-P, Leclerc E, Ranger J, Garbaye J, Uroz S, et al. Influence of forest trees on the distribution of mineral weathering-associated bacterial communities of the Scleroderma citrinum mycorrhizosphere. Appl Environ Microbiol. 2010; 76:4780-4787 